\title{
THE EFFECTS OF TEXT EDITING AND SUBTITLE PRESENTATION RATE ON THE COMPREHENSION AND READING PATTERNS OF INTERLINGUAL AND INTRALINGUAL SUBTITLES AMONG DEAF, HARD OF HEARING AND HEARING VIEWERS
}

\author{
Agnieszka Szarkowska ${ }^{1}$, Izabela KreJtz ${ }^{2}$, Olga PilipczuK ${ }^{3}$, \\ LUKASZ DUTKA ${ }^{4}$, JAN-LOUIS KRUGER ${ }^{5}$ \\ 1,3,4 Institute of Applied Linguistics, University of Warsaw \\ ul. Dobra 55, 00-312 Warsaw, Poland \\ Phone: +48 225526021 \\ E-mail: a.szarkowska@uw.edu.pl \\ E-mail: olga.pilipczuk@gmail.com \\ E-mail: lukasz.dutka@uw.edu.pl \\ ${ }^{2}$ Szkoła Wyższa Psychologii Społecznej \\ ul. Chodakowska 19/31, 03-815 Warsaw, Poland \\ Phone: + 48225179600 \\ E-mail: ikrejtz@swps.edu.pl \\ ${ }^{5}$ Macquarie University \\ Balaclava Road, NSW 2109 Sydney, Australia \\ Phone: +61449630802 \\ E-mail: janlouis.kruger@mq.edu.au
}

\begin{abstract}
In this paper we examine the influence of text editing (edited vs. verbatim subtitles) and subtitle presentation rates (12 vs. 15 characters per second) on the comprehension and reading patterns of interlingual and intralingual subtitles among a group of 44 deaf, 33 hard of hearing and 60 hearing Polish adult subjects. The results of the eyetracking study show no benefit of editing down the text of subtitles, particularly in the case of intralingual subtitling and deaf viewers. Verbatim subtitles displayed with the higher presentation rate yielded slightly better comprehension results, were skipped less often, and resulted in more effective reading patterns. Deaf and hard of hearing participants had lower comprehension than hearing people; they also had a higher number of fixations per subtitle and were found to dwell on subtitles longer than the hearing.
\end{abstract}

Keywords: subtitling, presentation rate, reading speed, verbatim, editing 


\section{INTRODUCTION}

In recent years we have witnessed an impressive growth in the use of subtitling. Thanks to technological advancements and accessibility legislation, its widespread use has resulted in an increased exposure of viewers to this mode of audiovisual translation. This proliferation of the mode necessitates more up-todate research on how subtitles are read and processed. The goal of this study is to provide empirical evidence in the ongoing debate on whether subtitling for the deaf and hard of hearing ${ }^{1}$ (SDH) should be verbatim or edited down, and whether the type of subtitling (intra- and interlingual subtitling) has any impact on this.

The degree of subtitle editing - both in inter- and intralingual subtitling - is inextricably linked with the subtitle presentation rate, ${ }^{2}$ typically measured in either characters per second (cps) or words per minute (wpm). The rate largely depends on the reading abilities of the expected target audience of a subtitled programme. The idea is that subtitles should remain on the screen for as long as readers need to be able to follow them comfortably. Children's cartoons will therefore have lower subtitle presentation rates than programmes for adult viewers. However, subtitles are typically presented at the rate that will be within the reading ability of the largest possible number of viewers. Pedersen (2011:133) quotes Akerberg, employee at SVT, Swedish public service broadcaster, as claiming that their goal is to make subtitles that "even every little old woman in every rural cottage" has time to read.

Given the limited amount of space available for subtitles on screen and the need to synchronise them with dialogue, conforming to the required presentation rate - particularly in the case of tightly-worded programmes - will inevitably result in the necessity to reduce the text. If not, the presentation rate would often have to be so high that subtitles would flash on screen and disappear without giving viewers a chance to read them. In general, the faster the pace of the dialogue and the lower the required subtitling presentation rate, the more editing (in the form of reduction, condensation and/or omission) will be necessary in subtitles.

\section{TEXT EDITING IN INTERLINGUAL VS. INTRALINGUAL SUBTITLING}

The degree of text editing in subtitles, i.e. whether subtitles should be verbatim or edited, has been one of the main bones of contention in subtitling (see Neves 2008; Robson 2004; Romero Fresco 2009; Szarkowska, Krejtz, Kłyszejko and Wieczorek 2011). It is important to note that the verbatim vs. edited dispute 
mainly relates to intralingual (e.g. English-to-English) subtitling rather than to interlingual subtitling (e.g. English-to-Polish). In standard interlingual subtitling, which contains a translation of foreign language dialogue for hearing viewers, the condensation and reduction of text on its way from spoken film dialogue to written subtitles is a widely accepted fact (see Díaz Cintas and Remael 2007; Georgakopoulou 2010; Tomaszkiewicz 2006).

In intralingual subtitling for the deaf and hard of hearing, however, the issue whether to edit subtitles and if so, to what degree, still remains a moot point. On the one hand, the main recipients of intralingual subtitling largely demand verbatim subtitles (see Neves 2008; Szarkowska and Laskowska 2014) on the grounds that they want to have full and equal access to the information presented in the auditory channel (see Robson 2004:20), which - when edited may be seen as a form of censorship (see Jensema et al. 1996:285). On the other hand, given that "hearing status and literacy tend to covary" (Burnham, Leigh, Noble, Jones, Tyler, Grebennikov and Varley 2008:392), many deaf people may experience difficulties in keeping up with the fast pace of verbatim subtitles (see Cambra, Silvestre and Leal 2009:425; Neves 2008:136).

\section{EFFECTS OF PRESENTATION RATE AND TEXT EDITING ON COMPREHENSION}

Subtitle presentation rate and text reduction are two parameters that can largely affect the comprehension of subtitled content. There are mixed accounts in the literature on whether edited subtitling indeed fosters comprehension. On the one hand, some studies have shown the benefits of text reduction and simplification on comprehension scores among deaf and hard of hearing viewers (see Burnham et al. 2008:392; Cambra et al. 2009), based on evidence that deaf people tend to have more reading difficulties and thus need slower subtitle presentation rates than the general population. An early study by Boyd and Vader (1972) showed that "captions adjusted to the linguistic level and reading rate of the viewers significantly improved information gain" (cited after Jelinek Lewis and Jackson 2001:44). In the same vein, Baker (1985) empirically showed that the reduced linguistic complexity of subtitles combined with reduced subtitle presentation rate $(60 \mathrm{wpm})$ resulted in improved comprehension for British school children. In a more recent study by Cambra et al. (2009), Spanish deaf children were found to have difficulty accessing information in subtitles owing to their poor reading skills and too fast subtitle presentation rates.

On the other hand, some researchers found that it is unreduced text that can facilitate comprehension (see Ewoldt 1984; de Linde and Kay 1999:30; Israelite and Helfrich 1988; Sundbye 1987; Yurkowski and Ewoldt 1986). This may be 
because reduced text tends to be more dense, less explicit and devoid of cohesive links than unreduced text (see Moran 2012). According to Schilperoord, de Groot and van Son (2005), text condensation in non-verbatim subtitling negatively affects textual coherence relations, making them less explicit, which in effect often leads to altering the implied meaning. In their 1999 study, de Linde and Kay reported that their participants obtained higher comprehension scores for verbatim subtitles compared to edited ones. A similar result was reported by Szarkowska et al. (2011), who found better comprehension rates for unreduced subtitles, with participants largely preferring verbatim subtitles. Jensema and Burch (1999) did not find any correlation between fast subtitle presentation rates and comprehension scores. Kruger (2013) investigated the impact of presentation rate (near-verbatim vs. edited) on comprehension and attention distribution in the context of educational subtitles, and also found no significant difference in comprehension, but some impact of presentation rate on attention distribution, with the higher rate resulting in reduced processing of subtitles.

On their part, Ward and colleagues (2007) compared deaf children's comprehension of audiovisual content with near-verbatim vs. edited captioning, showing that while no significant difference in comprehension between the types of subtitles was found in their study, the majority of participants expressed preference for edited subtitles. Tyler et al. (2009) showed that slowing down the subtitle presentation rate to $90 \mathrm{wpm}$ had no added benefit, and they suggested that the optimum presentation rate lies between $120 \mathrm{wpm}$ and 180 wpm. Finally, subtitle comprehension was found to largely depend on the level of literacy - and not necessarily on the hearing status - with better readers achieving higher scores (see Burnham et al. 2008; Tyler et al. 2009).

\section{RATIONALE AND HYPOTHESES}

Previous studies on text editing in subtitling focused mainly on intralingual subtitles in English watched by either deaf or hearing people. In Poland, where this study takes place, owing to statutory regulations requiring broadcasters to provide accessibility services, the most common type of subtitling on Polish television now - in the case of both domestic and foreign productions - is SDH. The usual reading speed for SDH on Polish television is $12 \mathrm{cps}$, whereas that of standard interlingual subtitling on DVD or cinema is $15 \mathrm{cps}$. Therefore, in order to reflect the reality of the audiovisual translation market, in this study we decided to use these two presentation rates.

The main research question we wanted to answer was whether - and if so, how - text editing and subtitle presentation rates affect comprehension and reading patterns of interlingual and intralingual subtitles in deaf, hard of hearing 
and hearing Polish adult viewers. With this question in mind, we formulated the following hypotheses:

(1) Text editing will have a positive effect on subtitle comprehension, i.e. verbatim subtitles displayed with a higher presentation rate will result in lower comprehension compared to edited subtitles displayed with the lower presentation rate.

(2) The type of subtitling (intra- and interlingual) will affect comprehension and reading patterns:

(2a) intralingual subtitles will have higher comprehension scores than interlingual subtitles,

(2b) intralingual subtitles will be skipped more often by hearing viewers than interlingual subtitles.

(3) Hearing loss will negatively impact comprehension.

(4) Hearing status will influence the subtitle reading patterns: deaf and hard of hearing viewers will spend more time in the subtitle area, have higher fixation count and skip fewer subtitles than hearing viewers.

\section{METHOD}

\subsection{Participants}

A group of 144 volunteers took part in the experiment, out of whom 44 were deaf, 33 hard of hearing and 60 hearing. Among them, 92 were female and 45 male $(67 \%$ vs. $33 \%$ respectively, see Table 1$)$. Due to calibration problems, data from 7 participants was discarded, leaving a total of 137. Participants were recruited in deaf and hard of hearing schools and associations, through social media, and the website of the AVT Lab research group. Convenience sampling was used.

Table 1

Participants by gender and hearing loss

\begin{tabular}{|l|c|c|c|}
\hline \multicolumn{1}{|c|}{ Gender } & Deaf & Hard of hearing & Hearing \\
\hline Female & 24 & 20 & 48 \\
\hline Male & 20 & 13 & 12 \\
\hline Total & 44 & 33 & 60 \\
\hline
\end{tabular}


We recruited participants from different age groups and with different onsets of hearing loss, from high school pupils to senior citizens, with a view to testing a heterogeneous and ecologically valid sample of target viewers.

Table 2

Participants by age

\begin{tabular}{|l|c|c|c|}
\hline \multicolumn{1}{|c|}{ Age } & Deaf & Hard of hearing & Hearing \\
\hline Mean (SD) & $26.43(14.99)$ & $29.94(15.03)$ & $29.33(11.25)$ \\
\hline Min. & 14 & 17 & 21 \\
\hline Max. & 67 & 70 & 63 \\
\hline
\end{tabular}

NOTE: There were no significant mean age differences between groups, $F(2,134)=0.82 \mathrm{~ns}$

Given that the subtitles in the study were in Polish, we wanted to know how many deaf and hard of hearing participants used Polish as their usual language of everyday communication and how many of them used Polish Sign Language (polski jezzyk migowy, PJM). The majority of deaf participants declared to use PJM and the majority of hard of hearing, Polish (see Table 3). ${ }^{3}$ Almost half of hard of hearing participants, however, declared to use PJM; these were mostly people with pre-lingual hearing loss. What this means is that for a large group of participants, Polish was a second/foreign language. This complex linguistic situation reflects the reality for these groups and therefore adds to the validity of the study in ecological terms.

Table 3

Language of everyday communication

\begin{tabular}{|l|c|c|c|c|}
\hline & Polish & $\begin{array}{c}\text { Polish Sign } \\
\text { Language }\end{array}$ & $\begin{array}{c}\text { Both Polish } \\
\text { and Polish Sign } \\
\text { Language }\end{array}$ & Other \\
\hline Deaf & $36 \%$ & $93 \%$ & $30 \%$ & $11 \%$ \\
\hline Hard of hearing & $88 \%$ & $48 \%$ & $33 \%$ & $6 \%$ \\
\hline
\end{tabular}

Since some of the videos used in the study were in English with Polish subtitles, we also asked the participants to self-report their proficiency in the English language on a scale from 1 to 10 , where 1 meant "I don't know the language at all" and 10 - "I am proficient". ${ }^{4}$ The highest proficiency was declared by hearing 
participants (7.98 out of 10), with deaf and hard of hearing people declaring lower proficiency (4.18 and 4.51, respectively).

\subsection{Procedure}

Participants were tested individually. First, they signed a written consent form to take part in the study. Then they were randomly assigned to one of the two versions of the experiment, which differed in the subtitle presentation rate (12 cps vs. $15 \mathrm{cps}$ ). Each version contained 12 subtitled videos lasting about 2 minutes. Participants were instructed to watch the videos carefully as they would have to answer questions related to the videos. The test began with a few questions eliciting demographic data. After viewing each video, participants answered three multiple-choice questions testing their comprehension. The questions were carefully prepared to test the comprehension of information which was only available in subtitles and was impossible to infer from the image. In total, participants answered 36 questions concerning audiovisual materials lasting together about 25 minutes. Finally, all participants received promotion kits from the University of Warsaw. An experiment session with one participant lasted about 45-50 minutes depending on the time a participant took to answer comprehension questions.

\subsection{Materials}

The videos were subtitled at either 12 or $15 \mathrm{cps}$, using EZTitles subtitling software. The $15 \mathrm{cps}$ version was equivalent to near-verbatim subtitles, whereas the 12 cps subtitles were edited down to conform with the lower reading speed requirements. The editing strategy used in the clips consisted of either removing a whole idea unit and leaving the remaining text intact, or - whenever this was not possible - by editing out individual words and phrases. The text that underwent reduction and omission included on the one hand elements of spoken discourse like false starts, repetitions, hesitations, reformulations, vocatives, and on the other hand, attributive adjectives, intensifiers, expletives, adverbials and other modifiers with limited propositional meaning.

The video clips represented three genres: (1) five feature films/TV series (two Polish clips with intralingual subtitles and three English clips with interlingual subtitles), (2) four documentaries (two Polish with intralingual subtitles and two English with interlingual subtitles) and (3) three news programmes (only Polish with intralingual subtitles). News programmes were only shown in Polish for the reasons of ecological validity. ${ }^{5}$ Each video was a self-contained 
scene and its understanding did not depend on familiarity with previous sequences of the film.

\subsection{Eye Movement Recording and Analysis}

Participants' eye movements were recorded with an SMI RED eye-tracking system with a sampling rate of $120 \mathrm{~Hz}$. Participants sat in front of a 22-inch LCD monitor with a resolution of $1920 \times 1200$ at a distance of about $60 \mathrm{~cm}$. Ninepoint calibration and validation were performed. To ensure high data quality, an average deviation of $1^{\circ}$ was the maximum value accepted during calibration. In the case of higher values, calibration was repeated. The eyetracker manufacturer's software Experiment Center and BeGaze were used with default settings to present stimuli and to analyse eyetracking data. For statistical analysis and data preparation, Stata 13.1 was used.

\section{RESULTS}

\subsection{Comprehension}

To test the differences in comprehension, we conducted a $3 \times 2 \times 2$ mixed ANOVA with group (deaf, hard of hearing, hearing), presentation rate (12 cps vs. $15 \mathrm{cps}$ ) and type of subtitles (intralingual and interlingual) as independent factors. The dependent variable was the percentage of correct answers. Post-hoc comparisons with Bonferroni correction were performed where necessary. Table 4 presents means for this analysis.

Table 4

Comprehension scores by subtitle presentation rate

\begin{tabular}{|l|c|c|c|c|c|}
\hline \multirow{2}{*}{} & \multicolumn{2}{|c|}{12 cps (edited) } & \multicolumn{2}{c|}{15 cps (verbatim) } & \multirow{2}{*}{ Mean } \\
\cline { 2 - 5 } & intralingual & interlingual & intralingual & interlingual & \\
\hline Deaf & $57.26 \%$ & $50.66 \%$ & $62.73 \%$ & $50.85 \%$ & $55.38 \%$ \\
\hline Hard of hearing & $73.55 \%$ & $70.96 \%$ & $75.38 \%$ & $69.82 \%$ & $72.43 \%$ \\
\hline Hearing & $78.79 \%$ & $81.94 \%$ & $80.39 \%$ & $82.43 \%$ & $80.87 \%$ \\
\hline Mean & $70.61 \%$ & $69.25 \%$ & $73.51 \%$ & $69.25 \%$ & $70.65 \%$ \\
\hline
\end{tabular}


Contrary to our initial hypothesis, comprehension was not higher in the case of the slower presentation rate with the higher degree of text editing. Although the differences between the two presentation rates did not reach statistical significance, we need to note that in the case of intralingual subtitles the comprehension scores were higher for all groups of participants in the verbatim condition $(15 \mathrm{cps})$ than in the edited condition $(12 \mathrm{cps})$.

The examination of differences in comprehension scores in the subtitling type condition (intra- vs. interlingual) revealed significant differences, which was in line with our hypotheses. The comprehension of videos with interlingual subtitles was significantly lower $\left(M_{\text {inter }}=0.69, S E=0.015\right)$ than that of videos with intralingual subtitles $\left(M_{\text {intra }}=0.72, S E=0.012\right), F(1,541)=4.1016$, $p=0.043$, eta ${ }^{2}=0.0057$. The interaction between this variable and the group variable also proved significant: $F(2,541)=4.5116, p=0.013$, eta ${ }^{2}=0.0114$. Deaf participants had higher comprehension scores for clips with intralingual subtitles $\left(M_{\text {dintra }}=0.60, S E=0.025\right)$ than with interlingual ones $\left(M_{d, \text { inter }}=0.51\right.$, $S E=0.026$ ), while the hearing group had slightly higher results for clips subtitled interlingually $\left(M_{\text {hearing,inter }}=0.82, S E=0.016, p=0.035\right)$ than intralingually ( $\left.M_{\text {hearing, } \text {, intra }}=0.80, S E=0.013\right)$.

Finally, in line with our hypotheses, comprehension results showed a significant main effect of group $F(2,541)=82.7190, p<0.001$, eta ${ }^{2}=0.2297$. Deaf participants were found to have significantly lower comprehension scores $\left(M_{d}=0.57, S E=0.027\right)$ than the remaining two groups $\left(M_{h o h}=0.73\right.$, $\left.S E=0.026, M_{\text {hearing }}=0.81, S E=0.0156\right)($ all $p$-values $<0.001)$.

\subsection{Eye Movements}

After comparing the comprehension scores, we examined differences in participants' eye movement patterns by analysing data from areas of interest (AOI) drawn around each subtitle. The following eyetracking metrics were used: mean fixation duration on AOI, dwell time (the sum of the duration of all fixations and saccades in the AOI, starting with the first fixation), dwell time as a percentage of visible time (the percentage of time that participants spent looking at the AOI out of the total subtitle display time), glances count (the number of times a saccade enters the AOI from outside - i.e. the number of times a person looked at the subtitle AOI), fixation count (the number of fixations in the AOI) and subject hit count (percentage of subtitle AOIs looked at by participants). For each of these parameters as the dependent variable, a $3 \times 2 \times 2$ ANOVA was performed with group (deaf, hard of hearing, hearing), presentation rate (12 cps vs. $15 \mathrm{cps}$ ) and type of subtitles (intralingual and interlingual) as independent factors. 
The data set on which the analyses were performed consisted of average values for the dependent variables calculated across three variables: participant number, presentation rate and type of subtitles. The resulting database comprised four entries for each of the participants: averages for the dependent variables with a presentation rate of $12 \mathrm{cps}$ and intralingual subtitles, with a presentation rate of $12 \mathrm{cps}$ and interlingual subtitles, and two entries with a rate of 15 cps: with intralingual and interlingual subtitles, ${ }^{6}$ altogether 548 entries.

\subsection{Presentation Rate}

The eyetracking analyses for the presentation rate (12 cps vs. $15 \mathrm{cps})$ showed two statistically significant main effects: in the number of glances $(p<0.001)$ and in dwell time as a percentage of visible time $(p=.009)$. The number of glances from the image to the subtitle area was higher in the case of edited subtitles than in the case of verbatim subtitles $\left(M_{12}=1.2787\right.$ vs. $M_{15}=1.1738$ per subtitle). This means that participants shifted their gaze more in clips with edited subtitles with the lower presentation rate. As regards dwell time as a percentage of visible time, participants spent proportionally less time watching subtitles displayed at $12 \mathrm{cps}$ ( $46 \%$ of subtitle display time) than those displayed at $15 \mathrm{cps}(50 \%)$. Deaf and hard of hearing participants spent significantly more time in the subtitle area than the hearing $\left(M_{\text {deaf }}=63.26 \%, M_{\text {hoh }}=58.89 \%\right.$, $\left.M_{\text {hearing }}=32.02 \%, p<.000\right)$.

Table 5

Descriptive statistics by presentation rate

\begin{tabular}{|c|c|c|c|c|}
\hline \multirow{2}{*}{ Group } & & \multicolumn{2}{|c|}{ Presentation rate } & \multirow{2}{*}{ Total } \\
\hline & & 12 & 15 & \\
\hline \multicolumn{5}{|c|}{ Dwell time on AOI (ms) } \\
\hline Deaf & $\begin{array}{l}\text { Mean } \\
\text { (SE) }\end{array}$ & $\begin{array}{c}1765 \\
(702.60)\end{array}$ & $\begin{array}{c}1674 \\
(557.69)\end{array}$ & $\begin{array}{c}1720 \\
(634.14)\end{array}$ \\
\hline Hard of hearing & $\begin{array}{l}\text { Mean } \\
\text { (SE) }\end{array}$ & $\begin{array}{c}1677 \\
(470.08)\end{array}$ & $\begin{array}{c}1567 \\
(424.00)\end{array}$ & $\begin{array}{c}1623 \\
(690.65)\end{array}$ \\
\hline Hearing & $\begin{array}{l}\text { Mean } \\
\text { (SE) }\end{array}$ & $\begin{array}{c}885 \\
(456.23)\end{array}$ & $\begin{array}{c}875 \\
(463.74)\end{array}$ & $\begin{array}{c}880 \\
(459.06)\end{array}$ \\
\hline Total & $\begin{array}{l}\text { Mean } \\
\text { (SE) }\end{array}$ & $\begin{array}{c}1359 \\
(690.65)\end{array}$ & $\begin{array}{c}1298 \\
(614.20)\end{array}$ & $\begin{array}{c}1328 \\
(653.64)\end{array}$ \\
\hline
\end{tabular}


Table 5 (continued)

\begin{tabular}{|c|c|c|c|c|}
\hline \multirow{2}{*}{ Group } & & \multicolumn{2}{|c|}{ Presentation rate } & \multirow{2}{*}{ Total } \\
\hline & & 12 & 15 & \\
\hline \multicolumn{5}{|c|}{ Dwell time in AOI as a percentage of visible time } \\
\hline Deaf & $\begin{array}{l}\text { Mean } \\
\text { (SE) }\end{array}$ & $\begin{array}{l}60.85 \% \\
(24.75)\end{array}$ & $\begin{array}{l}65.66 \% \\
(22.22)\end{array}$ & $\begin{array}{l}63.25 \% \\
(23.58)\end{array}$ \\
\hline Hard of hearing & $\begin{array}{l}\text { Mean } \\
\text { (SE) }\end{array}$ & $\begin{array}{c}56.5 \% \\
(15.08)\end{array}$ & $\begin{array}{r}61.27 \% \\
(16.64)\end{array}$ & $\begin{array}{c}58.89 \% \\
(16)\end{array}$ \\
\hline Hearing & $\begin{array}{l}\text { Mean } \\
\text { (SE) }\end{array}$ & $\begin{array}{l}30.25 \% \\
(15.96)\end{array}$ & $\begin{array}{l}33.79 \% \\
(17.82)\end{array}$ & $\begin{array}{l}32.02 \% \\
(16.97)\end{array}$ \\
\hline Total & $\begin{array}{l}\text { Mean } \\
\text { (SE) }\end{array}$ & $\begin{array}{l}46.4 \% \\
(23.81)\end{array}$ & $\begin{array}{l}50.64 \% \\
(24.21)\end{array}$ & $\begin{array}{l}48.52 \% \\
(24.09)\end{array}$ \\
\hline \multicolumn{5}{|c|}{ Fixation count per AOI } \\
\hline Deaf & $\begin{array}{l}\text { Mean } \\
(\mathrm{SE})\end{array}$ & $\begin{array}{c}6.53 \\
(2.37)\end{array}$ & $\begin{array}{c}6.54 \\
(1.98)\end{array}$ & $\begin{array}{c}6.53 \\
(2.17)\end{array}$ \\
\hline Hard of hearing & $\begin{array}{l}\text { Mean } \\
\text { (SE) }\end{array}$ & $\begin{array}{c}7.06 \\
(1.49)\end{array}$ & $\begin{array}{c}6.62 \\
(1.44)\end{array}$ & $\begin{array}{c}6.84 \\
(1.47)\end{array}$ \\
\hline Hearing & $\begin{array}{l}\text { Mean } \\
\text { (SE) }\end{array}$ & $\begin{array}{c}4.20 \\
(2.02)\end{array}$ & $\begin{array}{c}4.16 \\
(2.02)\end{array}$ & $\begin{array}{c}4.18 \\
(2.01)\end{array}$ \\
\hline Total & $\begin{array}{l}\text { Mean } \\
\text { (SE) }\end{array}$ & $\begin{array}{c}5.64 \\
(2.40)\end{array}$ & $\begin{array}{c}5.52 \\
(2.23)\end{array}$ & $\begin{array}{c}5.58 \\
(2.31)\end{array}$ \\
\hline \multicolumn{5}{|c|}{ Mean fixation duration (ms) } \\
\hline Deaf & $\begin{array}{l}\text { Mean } \\
\text { (SE) }\end{array}$ & $\begin{array}{c}237 \\
(62.52)\end{array}$ & $\begin{array}{c}226 \\
(50.42)\end{array}$ & $\begin{array}{c}231 \\
(56.77)\end{array}$ \\
\hline Hard of hearing & $\begin{array}{l}\text { Mean } \\
\text { (SE) }\end{array}$ & $\begin{array}{c}215 \\
(35.33)\end{array}$ & $\begin{array}{c}214 \\
(39.53)\end{array}$ & $\begin{array}{c}214 \\
(37.35)\end{array}$ \\
\hline Hearing & $\begin{array}{l}\text { Mean } \\
\text { (SE) }\end{array}$ & $\begin{array}{c}183 \\
(26.73)\end{array}$ & $\begin{array}{c}182 \\
(23.90)\end{array}$ & $\begin{array}{c}183 \\
(25.32)\end{array}$ \\
\hline Total & $\begin{array}{l}\text { Mean } \\
\text { (SE) }\end{array}$ & $\begin{array}{c}208 \\
(48.88)\end{array}$ & $\begin{array}{c}204 \\
(42.68)\end{array}$ & $\begin{array}{c}206 \\
(45.89)\end{array}$ \\
\hline
\end{tabular}


Table 5 (continued)

\begin{tabular}{|l|l|l|c|c|}
\hline \multirow{2}{*}{ Group } & \multirow{2}{*}{} & \multicolumn{2}{c|}{ Presentation rate } & \multirow{2}{*}{ Total } \\
\cline { 3 - 4 } & & $\mathbf{1 2}$ & $\mathbf{1 5}$ & \\
\hline \multicolumn{2}{|l|}{ Hit count (Percentage of subtitles looked at) } \\
\hline \multirow{2}{*}{ Deaf } & Mean & $\begin{array}{c}90.96 \\
(18.21)\end{array}$ & $\begin{array}{c}92.91 \\
(14.86)\end{array}$ & $\begin{array}{c}91.80 \\
(16.61)\end{array}$ \\
\hline \multirow{2}{*}{ Hard of hearing } & (SE) & $\begin{array}{l}98.25 \\
(3.44)\end{array}$ & $\begin{array}{c}97.19 \\
(4.82)\end{array}$ & $\begin{array}{c}97.72 \\
(4.21)\end{array}$ \\
\hline \multirow{2}{*}{ Hearing } & Mean & $\begin{array}{c}80.02 \\
(22.5)\end{array}$ & $\begin{array}{c}79.69 \\
(22.05)\end{array}$ & $\begin{array}{c}79.85 \\
(22.23)\end{array}$ \\
\hline \multirow{2}{*}{ Total } & Mean & $\begin{array}{c}87.84 \\
(19.62)\end{array}$ & $\begin{array}{c}88.15 \\
(18.61)\end{array}$ & $\begin{array}{c}87.99 \\
(19.10)\end{array}$ \\
\hline
\end{tabular}

Descriptive statistics for all the eyetracking variables by the subtitle presentation rate are presented in Table 5. Although not statistically significant, there are some interesting differences between the two presentation rates: for edited subtitles we observed longer dwell time, slightly higher fixation count, and longer mean fixation duration than for unedited subtitles.

\subsection{Language}

The language of the clip had a statistically significant effect on the processing of subtitles only as measured by dwell time ( $p=0.002$; main effect) and fixation count ( $p=0.011$; main effect). Dwell time was longer for clips with intralingual $\left(M_{\text {intra }}=1385 \mathrm{~ms}\right)$ than interlingual subtitles $\left(M_{\text {inter }}=1272 \mathrm{~ms}\right)$. Fixation count was also higher for intralingual subtitles $\left(M_{\text {intra }}=5.7301\right.$ vs. $\left.M_{\text {inter }}=5.4251\right)$. Table 6 presents descriptive statistics for eyetracking measures by the type of subtitling.

Pairwise comparisons of interaction terms by hearing status and language allowed us to gain more insight into the differences in dwell time. While the deaf and hard of hearing subjects had longer dwell times on intralingual subtitles $\left(M_{\text {d,intra }}=1840 \mathrm{~ms}\right.$ vs. $M_{\text {d,inter }}=1600 \mathrm{~ms}$ for the deaf, $p=0.030$, and $M_{\text {hoh,intra }}=1747 \mathrm{~ms}$ vs. $M_{\text {d,inter }}=1497 \mathrm{~ms}$ for the hard of hearing, $p=0.079$ ), the hearing subjects dwelt longer on interlingual subtitles than on intralingual ones ( $M_{\text {hearing,intra }}=855 \mathrm{~ms}$ vs. $M_{\text {hearing,inter }}=903 \mathrm{~ms}$ ); the difference between the two types of clips in the case of the hearing subjects is not statistically significant $(p=1)$. 
Table 6

Descriptive statistics by subtitling type

\begin{tabular}{|c|c|c|c|c|}
\hline \multirow{2}{*}{ Group } & & \multicolumn{2}{|c|}{ Subtitling type } & \multirow{2}{*}{ Total } \\
\hline & & Interlingual & Intralingual & \\
\hline \multicolumn{5}{|c|}{ Dwell time on AOI (ms) } \\
\hline Deaf & $\begin{array}{l}\text { Mean } \\
\text { (SE) }\end{array}$ & $\begin{array}{l}1599 \\
(649)\end{array}$ & $\begin{array}{l}1839 \\
(597)\end{array}$ & $\begin{array}{l}1719 \\
(634)\end{array}$ \\
\hline Hard of hearing & $\begin{array}{l}\text { Mean } \\
\text { (SE) }\end{array}$ & $\begin{array}{l}1496 \\
(445)\end{array}$ & $\begin{array}{l}1746 \\
(420)\end{array}$ & $\begin{array}{l}1621 \\
(449)\end{array}$ \\
\hline Hearing & $\begin{array}{l}\text { Mean } \\
\text { (SE) }\end{array}$ & $\begin{array}{c}908 \\
(465)\end{array}$ & $\begin{array}{c}851 \\
(452)\end{array}$ & $\begin{array}{c}880 \\
(459)\end{array}$ \\
\hline Total & $\begin{array}{l}\text { Mean } \\
\text { (SE) }\end{array}$ & $\begin{array}{l}1272 \\
(617)\end{array}$ & $\begin{array}{l}1384 \\
(684)\end{array}$ & $\begin{array}{l}1328 \\
(653)\end{array}$ \\
\hline \multicolumn{5}{|c|}{ Dwell time as a percentage of visible time } \\
\hline Deaf & $\begin{array}{l}\text { Mean } \\
\text { (SE) }\end{array}$ & $\begin{array}{l}60.6 \% \\
(25.1)\end{array}$ & $\begin{array}{l}65.9 \% \\
(21.77)\end{array}$ & $\begin{array}{l}63.25 \% \\
(23.58)\end{array}$ \\
\hline Hard of hearing & $\begin{array}{l}\text { Mean } \\
\text { (SE) }\end{array}$ & $\begin{array}{l}55.8 \% \\
(16.82)\end{array}$ & $\begin{array}{l}61.98 \% \\
(14.61)\end{array}$ & $\begin{array}{c}58.89 \% \\
(16)\end{array}$ \\
\hline Hearing & $\begin{array}{l}\text { Mean } \\
\text { (SE) }\end{array}$ & $\begin{array}{l}33.82 \% \\
(17.54)\end{array}$ & $\begin{array}{l}30.21 \% \\
(16.25)\end{array}$ & $\begin{array}{l}32.02 \% \\
(16.97)\end{array}$ \\
\hline Total & $\begin{array}{l}\text { Mean } \\
\text { (SE) }\end{array}$ & $\begin{array}{l}47.72 \% \\
(23.59)\end{array}$ & $\begin{array}{l}49.33 \% \\
(24.59)\end{array}$ & $\begin{array}{l}48.52 \% \\
(24.09)\end{array}$ \\
\hline \multicolumn{5}{|c|}{ Fixation count per AOI } \\
\hline Deaf & $\begin{array}{l}\text { Mean } \\
\text { (SE) }\end{array}$ & $\begin{array}{c}6.16 \\
(2.24)\end{array}$ & $\begin{array}{c}6.90 \\
(2.05)\end{array}$ & $\begin{array}{c}6.54 \\
(2.17)\end{array}$ \\
\hline Hard of hearing & $\begin{array}{l}\text { Mean } \\
\text { (SE) }\end{array}$ & $\begin{array}{c}6.39 \\
(1.46)\end{array}$ & $\begin{array}{c}7.29 \\
(1.36)\end{array}$ & $\begin{array}{c}6.84 \\
(1.47)\end{array}$ \\
\hline Hearing & $\begin{array}{l}\text { Mean } \\
\text { (SE) }\end{array}$ & $\begin{array}{c}4.35 \\
(2.02)\end{array}$ & $\begin{array}{c}4.05 \\
(1.99)\end{array}$ & $\begin{array}{c}4.18 \\
(2.01)\end{array}$ \\
\hline Total & $\begin{array}{l}\text { Mean } \\
\text { (SE) }\end{array}$ & $\begin{array}{c}5.43 \\
(2.19)\end{array}$ & $\begin{array}{c}5.73 \\
(2.42)\end{array}$ & $\begin{array}{c}5.58 \\
(2.31)\end{array}$ \\
\hline
\end{tabular}


Table 6 (continued)

\begin{tabular}{|c|c|c|c|c|}
\hline \multirow{2}{*}{ Group } & & \multicolumn{2}{|c|}{ Subtitling type } & \multirow{2}{*}{ Total } \\
\hline & & Interlingual & Intralingual & \\
\hline \multicolumn{5}{|c|}{ Mean fixation duration (ms) } \\
\hline Deaf & $\begin{array}{l}\text { Mean } \\
\text { (SE) }\end{array}$ & $\begin{array}{c}228 \\
(60.64)\end{array}$ & $\begin{array}{c}235 \\
(52.69)\end{array}$ & $\begin{array}{c}231 \\
(56.76)\end{array}$ \\
\hline Hard of hearing & $\begin{array}{l}\text { Mean } \\
\text { (SE) }\end{array}$ & $\begin{array}{c}211 \\
(39.44)\end{array}$ & $\begin{array}{c}218 \\
(35.13)\end{array}$ & $\begin{array}{c}214 \\
(37.35)\end{array}$ \\
\hline Hearing & $\begin{array}{l}\text { Mean } \\
\text { (SE) }\end{array}$ & $\begin{array}{c}180 \\
(25.16)\end{array}$ & $\begin{array}{c}186 \\
(25.22)\end{array}$ & $\begin{array}{c}183 \\
(25.32)\end{array}$ \\
\hline Total & $\begin{array}{l}\text { Mean } \\
\text { (SE) }\end{array}$ & $\begin{array}{c}203 \\
(47.63)\end{array}$ & $\begin{array}{c}209 \\
(43.93)\end{array}$ & $\begin{array}{c}206 \\
(45.90)\end{array}$ \\
\hline \multicolumn{5}{|c|}{ Hit count (Percentage of subtitles looked at) } \\
\hline Deaf & $\begin{array}{l}\text { Mean } \\
\text { (SE) }\end{array}$ & $\begin{array}{c}90.48 \\
(18.18)\end{array}$ & $\begin{array}{c}93.12 \\
(14.85)\end{array}$ & $\begin{array}{c}91.80 \\
(16.61)\end{array}$ \\
\hline Hard of hearing & $\begin{array}{l}\text { Mean } \\
\text { (SE) }\end{array}$ & $\begin{array}{c}97.40 \\
(4.6)\end{array}$ & $\begin{array}{c}98.03 \\
(3.7)\end{array}$ & $\begin{array}{c}97.72 \\
(4.2)\end{array}$ \\
\hline Hearing & $\begin{array}{l}\text { Mean } \\
\text { (SE) }\end{array}$ & $\begin{array}{c}83.27 \\
(21.94)\end{array}$ & $\begin{array}{c}76.44 \\
(22.08)\end{array}$ & $\begin{array}{c}79.85 \\
(22.23)\end{array}$ \\
\hline Total & $\begin{array}{l}\text { Mean } \\
\text { (SE) }\end{array}$ & $\begin{array}{c}88.99 \\
(18.77)\end{array}$ & $\begin{array}{c}87 \\
(19.41)\end{array}$ & $\begin{array}{c}87.99 \\
(19.10)\end{array}$ \\
\hline
\end{tabular}

For all variables except fixation duration on AOI, the interaction between group and language was significant, which means that whether and how the original language of the clip (and thereby subtitle type: intralingual vs. interlingual) influences the processing of subtitles depends on whether the person watching the clip is deaf, hard of hearing or hearing.

\subsection{Differences in Subtitle Processing Depending on Hearing Status}

We found that the group variable was significant $(p<0.001)$ in the case of all eyetracking measures: fixation duration on AOI, dwell time, dwell time as a percentage of visible time, glances count, fixation count and subject hit count; it 
also had the highest explanatory value with eta ${ }^{2}$ values ranging from $11.25 \%$ (glances count) to $36.87 \%$ (dwell time). The pairwise comparisons with posthoc Bonferroni corrections revealed that there is a significant difference in the eye movement patterns between the hearing and the hard of hearing subjects and between the hearing and the deaf subjects $(p s<0.001)$.

The mean fixation duration of hearing subjects was shorter $(183 \mathrm{~ms})$ than that of the hard of hearing $(214 \mathrm{~ms})$ and the deaf $(231 \mathrm{~ms})$. The same is true for dwell time on subtitles $\left(M_{\text {hearing }}=880 \mathrm{~ms}\right.$ vs. $M_{\text {hoh }}=1622 \mathrm{~ms}$ and $M_{d}=1720 \mathrm{~ms}$ respectively). Hearing subjects omitted more subtitles (subject hit count $M_{\text {hearing }}=79.86 \%$ ) than the hard of hearing (subject hit count $M_{\text {hoh }}=97.72 \%$ ) or the deaf $\left(M_{d}=91.80 \%\right)$. The number of fixations per subtitle was also lower for the hearing subjects $\left(M_{\text {hearing }}=4.1794\right)$ than the hard of hearing $\left(M_{h o h}=6.8425\right)$ and the deaf $\left(M_{d}=6.5355\right)$. The same is true for glances count $\left(M_{\text {hearing }}=\right.$ $1.0966, M_{h o h}=1.3906$ and $\left.M_{d}=1.2797\right)$. The differences between the deaf and the hard of hearing were below the significance threshold for fixation duration $(p<0.001)$, glances count $(p=0.013)$ and hit count $(p=0.010)$.

All pairwise comparisons of the interaction terms that hold the type of subtitles constant and change the group (e.g. comparison of eye movements of deaf subjects reading interlingual subtitles and hearing subjects reading interlingual subtitles; or hard of hearing subjects reading intralingual subtitles and hearing subjects reading intralingual subtitles) are significant whenever the hearing group is compared with the hard of hearing or the deaf group, with one exception - the difference between glances count for the deaf and the hearing with interlingual subtitles is not significant.

\section{DISCUSSION}

The goal of this study was to verify whether text reduction and subtitle presentation rate affect the comprehension and subtitle reading patterns of deaf, hard of hearing and hearing viewers watching intra- and interlingual subtitles. Contrary to our first hypothesis and some previous studies, we did not find any evidence that slower, edited subtitles resulted in better comprehension: in all groups of participants the higher presentation rate $(15 \mathrm{cps})$ with verbatim subtitles yielded slightly higher comprehension scores than the lower rate $(12 \mathrm{cps})$ with edited subtitles, but this difference did not reach statistical significance. The difference was most discernible in the case of Polish clips with intralingual subtitles watched by deaf and hard of hearing participants. This may suggest that contrary to the general belief, the higher degree of text editing combined with slower subtitle presentation rate does not necessarily foster the comprehension of subtitled videos. The lack of significant differences in comprehension 
corresponds to some earlier studies (see Jensema and Burch 1999; Kruger 2013).

In this study, the group that benefited most from unedited intralingual subtitles in terms of comprehension were the deaf. It was in this group that the difference between the verbatim and edited version in intralingual subtitles was most pronounced. Deaf and hard of hearing people are generally known to prefer verbatim subtitling (Szarkowska 2010; Szarkowska and Laskowska 2014) but, as noted by Jensema et al. (1996:286), they also "know they are not always getting perfect verbatim captioning because they sometimes see an actor speak a word or group of words for which there is no caption on the screen". Such discrepancies, disrupting intersemiotic cohesion between the visual and auditory channels in film, may cause perceptual confusion and result in poorer comprehension of edited subtitles. In a study on the impact of literal and non-literal translation strategies on the perception of subtitled film by hearing viewers, Ghia (2012) found that people tended to make more gaze shifts between the subtitles and the image when watching a clip with non-literal translation strategy, i.e. in the clip with a larger divergence between the source and the target text. This was also the case in our study, where edited subtitles induced more image-to-subtitle gaze shifts (glances count) than verbatim subtitles, which may be interpreted as contributing to a more disruptive reading process.

Better comprehension of unedited subtitles and greater ease of reading them may also be related to the internal cohesion of text - with the verbatim condition being more internally cohesive than the edited. Subtitle editing, mainly in the form of summarising the content and deleting coherence markers such as subordinating conjunctions, was shown by Schilperoord et al. (2005) to negatively affect coherence relations in discourse - both at the sentence and textual level. This is supported by a study on standard subtitling and hearing viewers by Moran (2012:209), who claimed that "subtitles containing more cohesive devices may be easier to process because of their linguistic coherence as well as their cohesiveness with the film text".

As regards differences in eyetracking measures between the two presentation rates, we found that the number of glances from the image to the subtitle area was higher in the case of edited subtitles than in the case of verbatim subtitles - despite $15 \mathrm{cps}$ subtitles being displayed longer as they contained more text. We believe this could be taken to mean that subtitle editing may contribute to people making more glances between the image and the subtitle text as they are constantly comparing both, possibly looking for (in)consistency, or perhaps as a result of such inconsistencies. Another reason for having a higher number of image-to-subtitle gaze shifts could stem from the fact that edited subtitles were displayed relatively long, which may have caused viewers to go back to the subtitle area after reading the subtitle and looking at the image, in the hope 
of finding a new subtitle while the previous one was still on screen. This, again, may have contributed to more disruptions in reading the edited subtitles with the lower presentation rate.

This finding is also supported by the slightly higher mean fixation duration we found in clips with edited subtitles displayed at the lower speed (208 ms for edited vs. $203 \mathrm{~ms}$ for verbatim subtitles) - longer fixation duration is often taken as an indication of higher processing effort. Along those lines, an analysis of fixation count and dwell time on subtitle AOI showed that the clips with edited subtitles induced slightly more fixations per subtitle (5.64) than verbatim subtitles (5.52) and that the total time spent in the subtitle area was longer for edited subtitles $(1359 \mathrm{~ms})$ than for verbatim subtitles $(1298 \mathrm{~ms})$. This was observed despite the fact that edited subtitles contained less text.

Taken together, the discussion above points to important benefits that verbatim subtitling may offer to viewers in contrast to edited subtitling. It turns out that apart from the seemingly obvious advantages often cited in the literature, subtitle editing does have important drawbacks which so far have not been adequately addressed in experimental studies.

In this study, we also found important variation in subtitle processing among the three groups of participants. Out of the three groups of people tested in our study, hearing people were the ones who spent significantly less time on subtitles, as manifested by shorter dwell time and lower fixation count as well as percentage of subtitles skipped. This is only natural given that hearing people did not need to rely on subtitles to the same extent as the deaf and hard of hearing, to whom they were indispensable to access the content from the auditory channel. In contrast to hearing people, deaf and hard of hearing participants in our study spent more time in the subtitle area, which was demonstrated by the higher dwell time and fixation count values. This is in line with some previous studies (Szarkowska et al. 2011; Krejtz et al. 2013).

Deaf and hard of hearing participants were also found to have a significantly longer mean fixation duration on AOIs $(231 \mathrm{~ms}$ in the case of the deaf and $214 \mathrm{~ms}$ of the hard of hearing) compared to hearing participants $(183 \mathrm{~ms})$. A longer duration of a fixation "is often associated with [...] more effortful cognitive processing" (Holmqvist et al. 2011:381). Combined with a significantly higher fixation count (6.54 fixations per subtitle for the deaf and 6.84 for the hard of hearing) and longer dwell time (1719 ms for the deaf and $1621 \mathrm{~ms}$ for the hard of hearing) compared to hearing participants (4.18 fixations per subtitle and $880 \mathrm{~ms}$ spent in the subtitle area), this may be interpreted as an indication of reading difficulties, some of which may possibly stem from the fact that for many deaf and hard of hearing viewers Polish was not the primary language of everyday communication. As "hearing status and literacy tend to covary" (Burnham et al. 2008:392), many deaf and hard of hearing people tend to 
achieve lower literacy levels than the hearing, which in turn means that they read subtitles more slowly. We also observed differences between the deaf and the hard of hearing group: although the hard of hearing had more fixations, they were shorter than in the case of the deaf participants, which may indicate less reading effort. Interestingly, the mean fixation duration was found to be the longest in the deaf group when watching the videos with edited subtitles at the lower presentation rate, which may indicate a larger cognitive effort necessary to process such edited subtitles than verbatim subtitles.

In line with our hypotheses related to differences in the processing of intraand interlingual subtitles, we found that hearing participants looked less at intralingual subtitles in Polish videos (4.05 fixations per subtitle, $851 \mathrm{~ms}$ spent in the subtitle area) and more at interlingual subtitles in English videos (4.35 fixations per subtitle, $908 \mathrm{~ms}$ in the subtitle area). As noted by Holmqvist et al. (2011:387), higher dwell time may indicate "higher informativeness of an object". While Polish-to-Polish subtitles were not necessary for hearing people to follow the film content, the subtitles in English clips had a more informative value for them. At the same time, higher dwell times in the subtitle area for both English and Polish clips found among the deaf $(1719 \mathrm{~ms})$ and hard of hearing $(1621 \mathrm{~ms})$ participants compared to hearing $(880 \mathrm{~ms})$ participants may be indicative of the difficulty in extracting information, uncertainty, and poor situation awareness (Holmqvist et al. 2011:387-388).

Another finding of this study is that the language of the video soundtrack, and thus the type of subtitling (intra- vs. interlingual), does have an impact on subtitle processing. This goes against some of the previously reported results, e.g. d'Ydewalle, van Rensbergen, Pollet 1987, who found that the time spent on reading the subtitles did not change as a function of the knowledge of the language spoken in the video or the availability of the soundtrack. In our study, the knowledge of the language spoken in the videos and the availability of the soundtrack was negatively related with the time spent looking at subtitles: hearing participants, whose proficiency in the languages spoken in the videos was generally higher than in the other two groups, spent less time gazing at all types of subtitles, particularly at intralingual Polish-to-Polish subtitles, in comparison with deaf and hard of hearing viewers, who had no or limited access to the soundtrack and limited knowledge of the languages spoken in the videos, particularly English. Yet, although many hearing participants were proficient in English and all of them were native speakers of Polish, they were still gazing a lot at both types of subtitles: they looked at as much as 83\% subtitles in English videos and $76 \%$ in Polish videos. This confirms previous studies, showing that subtitles are great gaze attractors (d'Ydewalle and de Bruycker 2007; Jensema 2000; Kruger et al. 2015). 
Our results also show that deaf and hard of hearing participants spent more time reading intralingual subtitles than interlingual ones, as indicated by a higher number of fixations (6.16 vs. 6.9 fixations per subtitle for the deaf and 6.39 vs. 7.29 for the hard of hearing, respectively) and longer dwell time in the subtitle AOI (1599 ms vs. $1839 \mathrm{~ms}$ for the deaf and $1496 \mathrm{~ms}$ vs. $1746 \mathrm{~ms}$ among the hard of hearing). This, combined with better comprehension of clips subtitled intralingually, may indicate that intralingual subtitles were processed more deeply by these two groups. This result may also be attributed to deaf and hard of hearing participants trying to lip-read and/or use their residual hearing when watching clips subtitled intralingually. In contrast, when watching English clips with interlingual subtitles, they could not lip-read or rely so much on residual hearing since, by their own admission, their proficiency in English was quite low (4.9 on the 10-point scale compared to 7 for hearing participants).

\section{Limitations of the Study}

An important limitation of this study is that in the two parameters tested: subtitle presentation rate (12 and $15 \mathrm{cps}$ ) and text reduction were conflated. Future studies should look into testing these two parameters independently in order to fine-tune the results (cf. Burnham et al. 2008; Tyler et al. 2009).

In this study, we did not assess the reading abilities of the participants through any literacy test or their proficiency in Polish. We believe that in future it would be important to assess the effects of the subtitle presentation rates relative to the reading/literacy levels of the participants, irrespective of the hearing status.

\section{CONCLUSION}

In this study, we aimed to test whether the subtitle presentation rate, the degree of text editing and subtitling type affect the comprehension and subtitle reading patterns of deaf, hard of hearing and hearing viewers. By examining a large and heterogeneous sample of target viewers, we sought to provide empirical evidence in the ongoing debate on whether subtitles should be verbatim or edited as well as whether there is any difference between intra- and interlingual subtitling in this respect.

Even though we expected to find more profound differences between the two subtitle presentation rates, we nevertheless observed a number of interesting results. Whereas the degree of subtitle editing turned out not to be of crucial importance in interlingual subtitles, in the case of intralingual subtitles the lack of excessive editing was beneficial particularly for people who are deaf or hard 
of hearing. Verbatim subtitles displayed at the higher presentation rate (15 cps) yielded slightly better comprehension scores, and were skipped less often. On the other hand, edited subtitles (12 cps) resulted in lower comprehension and slightly more disruptive reading patterns, as demonstrated by eyetracking measures. We therefore think that unedited subtitles displayed at $15 \mathrm{cps}$ were slightly more effective.

Future studies could further investigate differences in watching videos with intra- and interlingual subtitles in different language combinations, displayed at other presentation rates on larger samples of film material. It would also be interesting to experimentally examine text coherence relations in intralingual and interlingual subtitling.

\section{Acknowledgements}

This study was supported by research grant No. IP2011 053471 "Subtitling for the deaf and hard of hearing on digital television" from the Polish Ministry of Science and Higher Education for the years 2011-2014.

We would like to gratefully acknowledge the many contributors to this project, particularly Maria Logińska for her help in carrying out the tests; Instytut Głuchoniemych, Ośrodek Szkolno-Wychowawczy dla Głuchych, Fundacja Echo, and Polski Związek Głuchych for allowing us to conduct the study at their premises; Wojciech Figiel for his help in organizing the venue for the eyetracking tests; and finally, to all the d/Deaf, hard of hearing and hearing participants who gave their time for our study.

\section{Notes}

${ }^{1}$ Subtitling for the deaf and hard of hearing in Poland, where this study takes place, is both intralingual and interlingual (see Szarkowska 2013).

${ }^{2}$ The subtitle presentation rate is also referred to as reading speed (see Romero Fresco 2015; Tyler et al. 2009). $100 \%$.

${ }^{3}$ Participants could choose more than one option, hence the percentages do not add up to

${ }^{4}$ Since the main focus of the study was on subtitle reading patterns and it was already timeconsuming for the participants, we decided to rely on self-report rather than on conducting English language proficiency tests. We used the 1-10 scale as an easy and understandable way for all instead of asking the participants to use the Common European Framework of Reference for Languages (A1-C2) or any other official scale.

5 As opposed to films, there is no foreign-language television news programme in Poland which is available on TV with Polish translation.

${ }^{6}$ This is different from the typical procedure in studies of this type and stems from the construction of the study: each participant watched clips with all combinations of subtitle presentation rates and subtitle types. 


\section{References}

Baker R. 1985. Subtitling Television for Deaf Children. Media in Education Research Series Vol. 3. 1-46.

Becquemont, D. 1996. Le sous-titrage cinématographique: contraintes, sens, servitudes. In: Gambier, Y. (ed.) Les transfers linguistiques dans les médias audiovisuels. Villeneuve d'Ascq (Nord): Presses Universitaires du Septentrion. 145-155.

Boyd, J. \& Vader, E.A. 1972. Captioned Television for the Deaf. American Annals of the Deaf Vol 117. No. 1. 34-37.

Burnham, D., Leigh, G., Noble, W., Jones, C., Tyler, M., Grebennikov, L. \& Varley, A. 2008. Parameters in Television Captioning for Deaf and Hard of Hearing Adults: Effects of Caption Rate Versus Text Reduction on Comprehension. Journal of Deaf Studies and Deaf Education Vol. 13. No. 3. 391-404.

Cambra, C., Silvestre, N. \& Leal, A. 2009. Comprehension of Television Messages by Deaf Students at Various Stages of Education. American Annals of the Deaf Vol. 153. No. 5. 425-434.

d'Ydewalle, G., Rensbergen, J. V. \& Pollet, J. 1987. Reading a Message when the Same Message is Available Auditorily in Another Language: The Case of Subtitling. In: O'Reagan, J. K. \& Lévy-Schoen, A. (eds) Eye Movements: From Physiology to Cognition. Amsterdam, Netherlands: Elsevier. 313-321.

de Linde, Z. \& Kay, N. 1999. The Semiotics of Subtitling. Manchester: St. Jerome.

Díaz Cintas, J. \& Remael, A. 2007. Audiovisual Translation: Subtitling. Manchester: St. Jerome.

Ewoldt, C. 1984. Problems with Rewritten Materials, as Exemplified by 'To Build a Fire'. American Annals of the Deaf Vol. 129. 23-28.

Georgakopoulou, P. 2010. Reduction Levels in Subtitling. DVD Subtitling: A Convergence of Trends. Saarbrücken: Lambert Academic Publishing.

Ghia, E. 2012. The Impact of Translation Strategies on Subtitle Reading. In: Perego, E. (ed.) Eye Tracking in Audiovisual Translation. Aracne: Roma. 157-182.

Holmqvist, K. et al. 2011. Eyetracking. A Comprehensive Guide to Methods and Measures. Oxford: Oxford University Press.

Israelite, N. \& Helfrich M. 1998. Improving Text Coherence in Basal Readers: Effects of Revisions on the Comprehension of Hearing-Impaired and Normal-Hearing Readers. Volta Review Vol. 90. 261-276.

Jelinek Lewis M. S. \& Jackson, D.W. 2001. Television Literacy: Comprehension of Program Content Using Closed Captions for the Deaf. Journal of Deaf Studies and Deaf Education Vol. 6. 43-53.

Jensema, C. \& Burch, R. 1999. Caption Speed and Viewer Comprehension of Television Programs. http://www.dcmp.org/caai/nadh135.pdf

Jensema, C. 1998. Viewer Reaction to Different Television Captioning Speeds. American Annals of the Deaf Vol. 143. No. 4. 318-324.

Jensema, C., McCann, R. \& Ramsey, S. 1996. Closed-Captioned Television Presentation Speed and Vocabulary. American Annals of the Deaf Vol. 141. No. 4. 284-292.

Krejtz, I., Szarkowska, A., \& Krejtz, K. 2013. Effects of Shot Changes on Eye Movements in Subtitling. Journal of Eye Movement Research Vol. 6. No. 5. 3, 1-12.

Kruger, J.-L. 2013. Subtitles in the Classroom: Balancing the Benefits of Dual Coding with the Cost of Increased Cognitive Load. Journal for Language Teaching Vol. 47. No. 1. 29-53.

Kruger, J.-L., Szarkowska, A. \& Krejtz, I. 2015. Subtitles on the Moving Image: An Overview of Eye Tracking Studies. Refractory: A Journal of Entertainment Media Vol. 25. 1-14.

Martí Ferriol, J. L. 2013. Subtitle Reading Speed. A New Tool for its Estimation. Babel Vol. 59. No. 4. $406-420$. 
Moran, S. 2012. The Effect of Linguistic Variation on Subtitle Reception. In: Perego, E. (ed.) Eye Tracking in Audiovisual Translation. Roma: Aracne Editrice. 183-222.

Neves, J. 2008. Ten Fallacies about Subtitling for the d/Deaf and the Hard of Hearing. Journal of Specialised Translation Vol. 10. 128-143.

Pedersen, J. 2011. Subtitling Norms on Television. An Exploration Focussing on Extralinguistic Cultural References. Amsterdam/Philadelphia: John Benjamins.

Robson, G. 2004. The Closed Captioning Handbook. Amsterdam: Elsevier.

Romero Fresco, P. 2009. More Haste than Speed: Edited versus Verbatim Respoken Subtitles. Vigo International Journal of Applied Linguistics Vol. 6. 109-133.

Romero-Fresco, P. 2015. The Reception of Subtitles for the Deaf and Hard of Hearing in Europe. Bern: Peter Lang.

Schilperoord, J., de Groot, V. \& van Son, N. 2005. Nonverbatim Captioning in Dutch Television Programs: A Text Linguistic Approach. Journal of Deaf Studies and Deaf Education Vol. 10. No. 4. 402-416.

Sundbye, N. 1987. Text Explicitness and Inferential Questioning: Effects on Story Understanding and Recall. Reading Research Quarterly Vol. 22. 82-98.

Szarkowska A. 2010. Accessibility to the Media by Hearing Impaired Audiences in Poland: Problems, Paradoxes, Perspectives. In: Díaz Cintas, J., Matamala, A. \& Neves, J. (eds) New Insights into Audiovisual Translation and Media Accessibility. Media for All Vol. 2. Amsterdam-New York: Rodopi. 139-158.

Szarkowska, A., Krejtz, I., Kłyszejko, Z. \& Wieczorek, A. 2011. Verbatim, Standard, or Edited? Reading Patterns of Different Captioning Styles among Deaf, Hard of Hearing, and Hearing Viewers. American Annals of the Deaf Vol. 156. No. 4. 363-378.

Szarkowska, A. \& Laskowska, M. 2014. Jakie Powinny Być Napisy? Raport z badania preferencji widzów na temat napisów telewizyjnych. ['What should subtitles be like? A report on viewers' preferences concerning television subtitling.'] http://avt.ils.uw.edu.pl/files/2014/07/ Jakie-powinny-byc-napisy_Raport.pdf

Szarkowska, A. 2013. Towards Interlingual Subtitling for the Deaf and Hard of Hearing. Perspectives Vol. 21. No. 1. 68-81. http://dx.doi.org/10.1080/0907676X.2012.722650.

Szarkowska, A., Krejtz, I., Kłyszejko, Z. \& Wieczorek, A. 2015. Eyetracking in Poland. In: Romero-Fresco, P. (ed.) The Reception of Subtitles for the Deaf and Hard of Hearing in Europe. Bern: Peter Lang. 235-262.

Tomaszkiewicz, T. 2006. Przekład Audiowizualny ['Audiovisual translation']. Warszawa: PWN.

Tyler, M. D., Jones, C., Grebennikov, L., Leigh, G., Noble, W. \& Burnham, D. 2009. Effect of Caption Rate on the Comprehension of Educational Television Programmes by Deaf School Students. Deafness and Education International Vol. 11. No. 3. 152-162.

Ward, P., Wang, Y., Paul. P. \& Loeterman, M. 2007. Near-Verbatim Captioning versus Edited Captioning for Students who are Deaf or Hard of Hearing: A Preliminary Investigation of Effects on Comprehension. American Annals of the Deaf Vol. 152. No. 1. 20-28.

Yurkowski P. \& Ewoldt C. 1986. A Case for the Semantic Processing of the Deaf Reader. American Annals of the Deaf Vol. 131. 243-247. 